\title{
Methodology to assess end-of-life anaerobic biodegradation kinetics and methane production potential for composite materials
}

\section{Authors: Cecily A. Ryan, Sarah L. Billington, \& Craig S. Criddle}

NOTICE: this is the author's version of a work that was accepted for publication in Composites Part A: Applied Science and Manufacturing. Changes resulting from the publishing process, such as peer review, editing, corrections, structural formatting, and other quality control mechanisms may not be reflected in this document. Changes may have been made to this work since it was submitted for publication. A definitive version was subsequently published in Composites Part A: Applied Science and Manufacturing [VOL\# 95, (April 2017)] DOI\# 10.1016/j.compositesa.2017.01.014

Ryan, Cecily A., Sarah L. Billington, and Craig S. Criddle. "Methodology to assess end-oflife anaerobic biodegradation kinetics and methane production potential for composite materials." Composites Part A: Applied Science and Manufacturing 95 (July 2107): 388-399. DOI: 10.1016/j.compositesa.2017.01.014.

Made available through Montana State University's $\underline{\text { ScholarWorks }}$ scholarworks. montana.edu 


\title{
Methodology to assess end-of-life anaerobic biodegradation kinetics and methane production potential for composite materials
}

\author{
Cecily A. Ryan*, Sarah L. Billington, Craig S. Criddle \\ Department of Civil and Environmental Engineering, Stanford University, Stanford, CA 94305, United States
}

\begin{abstract}
A B S T R A C T
Composites made with bio-based resins are promising candidates for replacement of conventional plastic composites made with petroleum-based resins in many applications (e.g., decking, paneling, furniture, molded automotive parts). For any such applications, end-of-life management needs consideration. Here, we describe a methodology to assess end-of-life anaerobic degradation to methane $\left(\mathrm{CH}_{4}\right)$ within landfills or anaerobic digestion (AD) facilities in batch anaerobic microcosms. The core methodology combines stoichiometric considerations, chemical oxygen demand (COD) analysis, a $\mathrm{CH}_{4}$ production assay, and modeling. Additional analyses, such as thermogravimetric analysis (TGA), can complement this core set of analyses. We apply the methodology to injection molded poly(hydroxybutyrateco-hydroxyvalerate) (PHBV) composites with wood fiber (WF) $(0 \%, 20 \%, 40 \%)$ and two fiber-matrix compatibilization treatments that enhance in-service performance: (1) hydrophobic silane treatment of the WF and (2) grafting of hydrophilic maleic anhydride groups to the PHBV matrix. The methodology successfully quantifies process kinetics, ultimate $\mathrm{CH}_{4}$ production capacity, and biodegradability, and allows comparison to reference materials (positive controls).
\end{abstract}

\section{Introduction}

Growing concern over non-renewable petroleum-based plastics and the fate of these materials in the environment and landfills has led to increased interest in biobased and biorenewable plastics and composites as replacements for less sustainable options [1,2]. Building and construction materials are of particular interest because debris from construction and demolition operations comprises approximately $40 \%$ of the US landfill volume [3]. To date, performance studies with composite materials have largely focused on in-use processing and material properties. This evaluation is a necessary first step for materials characterization, but endof-life information is needed for complete life cycle assessments, particularly for anaerobic environments such as landfills and anaerobic digestion (AD) facilities. Standardized methodologies are therefore needed to assess the anaerobic biodegradation potential of composites. Here, we addresses this issue.

We first propose a generic methodology for assessment of the anaerobic biodegradability of composite materials involving the following steps: (1) materials characterization, (2) a methane pro-

\footnotetext{
* Corresponding author at: Department of Mechanical and Industrial Engineering, Montana State University, P.O. Box 173800, Bozeman, MT 59717, United States.

E-mail address: cecily.ryan@montana.edu (C.A. Ryan).
}

duction assay, (3) modeling of assay results, and (4) calculation of biodegradability.

We then apply this methodology to injection molded poly (hydroxybutyrate-co-hydroxyvalerate) (PHBV) composites with wood fiber (WF) $(0 \%, 20 \%, 40 \%)$ and two fiber-matrix compatibilization treatments that enhance in-service performance: (1) hydrophobic silane treatment of the WF and (2) grafting of hydrophilic maleic anhydride groups to the PHBV matrix. We demonstrate that this methodology successfully quantifies process kinetics, ultimate methane $\left(\mathrm{CH}_{4}\right)$ production capacity, and biodegradability, and allows comparison to reference materials (positive controls).

\section{Methodology}

\subsection{Materials characterization}

Fully characterizing the resin and fiber components of composite materials is important for accurately predicting $\mathrm{CH}_{4}$ production from AD. Three critical parameters for establishing composite ultimate $\mathrm{CH}_{4}$ yield and biodegradability are: (i) fiber fraction, (ii) determining the stoichiometry of $\mathrm{CH}_{4}$ production for components with known compositions, and (iii) establishing the stoichiometry 
of components with an unknown composition, which can be determined using chemical oxygen demand (COD) assays.

\subsubsection{Fiber fraction}

Knowledge of fiber content of the composites is important because it affects total biogas production as well as in-service mechanical properties. The weight percent of fiber can be determined as per ASTM D3171 [4]. Composite samples are weighed, the resin matrix is dissolved in a suitable solvent, and the fiber is extracted from the solvent, collected, dried, and weighed. The amount of fiber by weight is calculated by:

Fiber Weight Percent $=W_{f} \times 100 \%=\frac{M_{\text {fiber }}}{M_{\text {composite }}} \times 100 \%$

where $W_{f}, M_{\text {fiber }}$ is the mass of the fiber measured post-dissolution and $M_{\text {composite }}$ is the mass of the composite sample as measured predissolution.

\subsubsection{Stoichiometry of components with known composition}

When the molecular or empirical formula of a composite material is known, the stoichiometry for complete anaerobic biodegradation into $\mathrm{CH}_{4}$ and carbon dioxide $\left(\mathrm{CO}_{2}\right)$ can be assessed [5]:

$$
\begin{aligned}
& \mathrm{C}_{n} \mathrm{H}_{a} \mathrm{O}_{b}+\left(n-\frac{a}{4}-\frac{b}{2}\right) \mathrm{H}_{2} \mathrm{O} \longrightarrow\left(\frac{n}{2}-\frac{a}{8}+\frac{b}{4}\right) \mathrm{CO}_{2} \\
& +\left(\frac{n}{2}+\frac{a}{8}-\frac{b}{4}\right) \mathrm{CH}_{4}
\end{aligned}
$$

This equation is used to predict the theoretical $\mathrm{CH}_{4}$ production potential $\left(\mathrm{ThCH}_{4}\right)$ for substrates with known compositions, such as bioplastic resins and control samples. Eq. (2) does not account for substrate conversion to biomass, so the practical upper limit for this process is somewhat less [6].

\subsubsection{Stoichiometry of components with unknown composition}

In the absence of information regarding the stoichiometry of a material, the chemical oxygen demand (COD) can be measured, as per standard methods (Hach Company [7]), and used to predict $\mathrm{ThCH}_{4}$ production. COD is a measure of the oxygen required to completely oxidize an organic sample, and for an organic with a known COD (measured or calculated) $0.35 \mathrm{~L} \mathrm{CH}_{4} / \mathrm{g}$ COD at STP and $0.398 \mathrm{~L} \mathrm{CH} / \mathrm{g} \mathrm{COD}$ at $37^{\circ} \mathrm{C}$ is produced. The methods described by Hach are modified for solid substrates by slicing or weighing out $\sim 1-2 \mathrm{mg}$ of the component to be tested, and adding it to the COD vial along with $2 \mathrm{~mL}$ of deionized (DI) water to obtain the appropriate dilution.

\subsection{Methane production assay}

The $\mathrm{CH}_{4}$ production assay is based on volumetric $\mathrm{CH}_{4}$ measurements from batch anaerobic microcosms. Evaluation of $\mathrm{CH}_{4}$ production requires: (i) selection of positive controls and bioplastic reference samples, (ii) pre-degradation sample preparation, (iii) preparation of anaerobic media and selection and addition of inoculum, (iv) volumetric measurement of $\mathrm{CH}_{4}$ production, and (v) monitoring biogas composition over the time of degradation.

\subsubsection{Positive and negative controls and bioplastic reference samples}

Positive controls are readily biodegradable materials (in an anaerobic environment) with a known $\mathrm{ThCH}_{4}$ production, such as microcrystalline $\alpha$-cellulose [8]. Positive controls are considered to have fully biodegraded at $80 \% \mathrm{ThCH}_{4}$ and are tested in duplicate or triplicate. The mass of positive control added to each bioreactor is calculated from the COD/weight ratio of the positive control and the bioplastic test samples, such that the same weight of COD is added to each bioreactor.
In addition to positive controls, negative controls (i.e., inoculated anaerobic media) are tested in order to subtract $\mathrm{CH}_{4}$ production activity due to the inoculum seed from $\mathrm{CH}_{4}$ produced from biocomposite samples. Negative controls are run in triplicate.

Neat bioplastic samples are also used as reference samples for biocomposite degradation. Any bioplastic matrix treatments are fabricated into bioplastic reference samples for biocomposites with those treatments. These samples are tested in duplicate or triplicate. A sample mass of $\sim 0.25-2 \mathrm{~g}$ can be analyzed in $500-\mathrm{mL}$ bioreactors, using this assay.

\subsubsection{Sample preparation}

To obtain an accurate pre-degradation sample weight for use in $\mathrm{CH}_{4}$ production calculations, samples are dried in a vacuum desiccator for 1 week and then weighed. For some materials, a low temperature drying oven is also appropriate. It is important to retrieve, dry, and weigh any remaining un-degraded composite material after the assay. In order to retrieve remaining sample matter post-experiment, samples are placed in non-degradable mesh bags with a mesh size such that un-degraded composite components are retained, but micoorganisms can freely access composite surfaces during degradation. To control for any experimental variability that could be introduced from the mesh bags, the bags should also be included in the positive and negative control vessels.

\subsubsection{Preparation of anaerobic media and inoculum}

Standardizing anaerobic media and the addition of inoculum to the batch microcosms is critical for repeatability of results. The anaerobic mineral media chosen for this assay was based on standard solutions as described in ASTM D5210-92 [9], with modifications based upon other studies of anaerobic degradation [10-12]. The following 4 concentrated stock solutions are used: (S1) resazurin, $0.5 \mathrm{~g} / \mathrm{L}$; (S2) $\mathrm{KH}_{2} \mathrm{PO}_{4}, 69 \mathrm{~g} / \mathrm{L}, \mathrm{K}_{2} \mathrm{HPO}_{4}, 88 \mathrm{~g} / \mathrm{L}, \mathrm{NH}_{4} \mathrm{Cl}, 100 \mathrm{~g} / \mathrm{L}$; (S3) $\mathrm{MgCl}_{2} \cdot 6 \mathrm{H}_{2} \mathrm{O}, \quad 60 \mathrm{~g} / \mathrm{L}, \quad \mathrm{CaCl}_{2} \cdot 2 \mathrm{H}_{2} \mathrm{O}, \quad 45 \mathrm{~g} / \mathrm{L}, \quad \mathrm{FeCl}_{2}, \quad 12 \mathrm{~g} / \mathrm{L}$, $\mathrm{MnCl}_{2} \cdot 4 \mathrm{H}_{2} \mathrm{O}, 400 \mathrm{mg} / \mathrm{L}, \mathrm{CoCl}_{2} \cdot 6 \mathrm{H}_{2} \mathrm{O}, 400 \mathrm{mg} / \mathrm{L}, \mathrm{NiCl}_{2} \cdot 6 \mathrm{H}_{2} \mathrm{O}, 50 \mathrm{mg} /$ $\mathrm{L}, \mathrm{CuCl}_{2}, 50 \mathrm{mg} / \mathrm{L}, \mathrm{ZnSO}_{4} \cdot 7 \mathrm{H}_{2} \mathrm{O}, 105 \mathrm{mg} / \mathrm{L}, \mathrm{H}_{3} \mathrm{BO}_{3}, \mathrm{mg} / \mathrm{L}, \mathrm{Na}_{2} \mathrm{MoO}_{4}$. $2 \mathrm{H}_{2} \mathrm{O}, 50 \mathrm{mg} / \mathrm{L}, \mathrm{Na}_{2} \mathrm{SeO}_{3}, 10 \mathrm{mg} / \mathrm{L}$; and (S4) $\mathrm{Na}_{2} \mathrm{~S} \cdot 9 \mathrm{H}_{2} \mathrm{O} 50 \mathrm{~g} / \mathrm{L}$. These 4 stock solutions are used in the same proportions as in ASTM D5210 to make the media, following the preparation instructions included in the standard. Bicarbonate $\left(\mathrm{NaHCO}_{3}\right)$ is added to give a final concentration of $50 \mathrm{mM}$ in the media.

Inoculum should be selected from a mixed anaerobic microbial community, such as sludge obtained from an anaerobic digester at a municipal wastewater treatment facility. The media is continuously stirred and sparged with $\mathrm{N}_{2} / \mathrm{CO}_{2}$ 70:30 (Praxair certified standard, NI CD30C-K) during the addition of the inoculum to maintain anaerobic conditions. Anaerobic digester sludge is added as an inoculum to the anaerobic mineral media at $10 \mathrm{vol} . \%$ of the total volume, as per ASTM D5210 [9]. Inocula should be stored in the dark at $37^{\circ} \mathrm{C}$ for two weeks prior to initiating experiments in order to decrease background biogas production from the inoculum seed. Prior to testing, the sludge is screened through a $1 \mathrm{~mm}$ mesh sieve followed by a single layer of cheese cloth in order to reduce grit and large solids that could interfere with the experiment. This step is performed immediately before adding the inoculum to the anaerobic media.

The operational $\mathrm{pH}$ range for methanogens in biological wastewater treatment is $\sim 6.4-7.8$, with optimal ranges to accurately model $\mathrm{CH}_{4}$ production between 6.8 and 7.6 [13,14]. The buffered media described herein was selected to maintain this optimal range for the duration of composite degradation. Measuring the $\mathrm{pH}$ of the inoculated media prior to testing is important for assuring that the $\mathrm{CH}_{4}$ production can be modeled as described in Section 2.3. If $\mathrm{CH}_{4}$ production initiates, lags, and then recovers, additional buffering capacity may be required. Procedures to measure chemical oxygen demand (COD), $\mathrm{pH}$, suspended solids (SS), volatile 
suspended solids (VSS), and alkalinity should be performed in accordance with Standard Methods for the Examination of Water and Wastewater [15].

\subsubsection{Volumetric measurement of methane}

Accurate volumetric measurement of $\mathrm{CH}_{4}$ production from composite samples is critical for assessing the ultimate $\mathrm{CH}_{4}$ yield and extent of biodegradability. An automated, flowthrough gas meter makes this measurement feasible for largevolume composite materials. The Automatic Methane Test Setup (AMPTSII) from Bioprocess Control is one such system. To create the batch anaerobic microcosms, each sample is placed in 500$\mathrm{mL}$ media bottles (600 mL total volume), then filled with $500 \mathrm{~mL}$ of inoculated anaerobic media, leaving $100 \mathrm{~mL}$ of gas headspace. The bottles are stoppered and the headspace sparged with $\mathrm{N}_{2} / \mathrm{CO}_{2} 70: 30$ before and during filling to maintain anaerobic conditions in the sample containers. The media is continuously mixed during filling with a magnetic stirrer and by gas agitation from being sparged with $\mathrm{N}_{2} / \mathrm{CO}_{2}$. Reactors are filled sequentially; media should be pumped continuously with a bellows metering pump (such as GRI 14251-003). Once filled, the bottles are connected with viton tubing to the AMPTSII gas measuring setup. The bioreactors are submerged in a water bath set at $37^{\circ} \mathrm{C}$.

\subsubsection{Biogas composition}

Gas sampling “T's” (obtained through BioProcess Control via SeaHold LLC) inline after the reactor headspace and before the $\mathrm{CO}_{2}$ traps can be used to sample the gas composition during degradation. These glass sampling ports are fit with $13 \mathrm{~mm}$ butyl rubber/ Teflon stoppers (Kimble Chase, Part No. 73811T-13) and sealed with $13 \mathrm{~mm}$ tear-off aluminum crimp seals. Stoppers and seals should be replaced prior to each experimental run. The inline $\mathrm{CO}_{2}$ traps are filled with $3 \mathrm{M}$ sodium hydroxide with a thymolphthalein $\mathrm{pH}$ indicator. $\mathrm{CH}_{4}$ is measured volumetrically in increments of approximately $10 \mathrm{~mL}$ (the reservoir volume of each calibrated channel).

Biogas samples are collected using a gas tight syringe and analyzed using gas chromatography (GC). The relative amounts of $\mathrm{CH}_{4}$ and $\mathrm{CO}_{2}$ in the headspace relates to the stoichiometry of the composite components (Eq. (2)).

\subsection{Modeling of assay results}

Several models are used to describe microbial growth and product formation, such as $\mathrm{CH}_{4}$ production, in anaerobic systems [16-20]. Previously, the authors evaluated a set of these models and found that a good fit of $\mathrm{CH}_{4}$ production and degradation of bioplastic was obtained with the Gompertz model [14]:

$P(t)=P_{m} \cdot \exp \left\{-\exp \left[\frac{R \cdot e}{P_{m}}(\lambda-t)+1\right]\right\}$

where $P(t)$ is the product $\left(\mathrm{CH}_{4}\right)$ volume released over time, $P_{m}$ is the methane production potential $[\mathrm{mL} / \mathrm{g}$ ], $\lambda$ is the lag phase time [days], and $R$ is the maximum specific $\mathrm{CH}_{4}$ production rate $[\mathrm{mL} / \mathrm{g}$ day]. Because the Gompertz model provides a good fit to the data and parameter interpretation is straightforward, it is adopted in this methodology to compare anaerobic biodegradability of different composite materials.

\subsection{Calculation of biodegradability}

Anaerobic biodegradability is measured using $\mathrm{CH}_{4}$ production volume. Biodegradability is expressed as a percentage of the $\mathrm{CH}_{4}$ measured divided by the $\mathrm{ThCH}_{4}$ :

$\%$ Biodegradability $=\frac{\text { Measured } \mathrm{CH}_{4}}{\text { Theoretical } \mathrm{CH}_{4}} \times 100 \%$

For components with a known stoichiometry, theoretical calculations are based on Eq. (2). For complex substrates with an unknown composition, $\mathrm{ThCH}_{4}$ is calculated from the measured COD (Section 2.1.3). For lignocellulosic fibers, the bio-availability of the different sub-components within the biomass matrix impacts the actual methane production potential measured experimentally, and thus biodegradability.

Biodegradability, as calculated by $\mathrm{CH}_{4}$ production, can be compared with sample weight loss measurements, ideally conducted as a parallel experiment so as to not disrupt gas production, the anaerobic microbial community, or microorganisms attached to the composite surface. A challenge in using weight loss measurements for calculation of biodegradability is accurately collecting and quantifying the constituents of partially degraded composite materials. Therefore, as the $\mathrm{CH}_{4}$ production measurements give a more accurate indication of the composite materials that are bioavailable, it is recommended to use this method for quantitative assessment of biodegradability [6]. However, having samples which are removed from the degradation environment for additional analysis can be beneficial in assessing the materials properties of the composite in intermediate stages of degradation.

\section{Example application of methodology: PHBV-WF composites}

Bioderived aliphatic polyesters such as poly(hydroxyalkanoates) (PHAs) are of interest for biocomposite applications as they can be (i) synthesized from sugars, oils, and biogas methane [21,22], (ii) processed using equipment standard to petroleumbased thermoplastics, (iii) tailored so that their in-service material properties are similar to many traditional plastics [23], and (iv) anaerobically degraded into a methane-rich biogas at end-of-life $[24,25]$. The methane can then be used as a biofuel or as a feedstock for additional PHA production. One of the most widely studied and available PHA is poly(hydroxybutyrate) (PHB) and its copolymer PHBV. PHBV is a semicrystalline thermoplastic with mechanical properties similar to that of polypropylene $[23,26]$. Adding natural fibers, such as wood fiber (WF), to PHBV to make biocomposites can improve mechanical properties, make use of recycled waste streams, and reduce cost over that of neat PHBV [27-29]. In previous work, two compatibilization treatments for the WF and PHBV matrix were examined to enhance mechanical properties and in-service durability $[29,30]$, but the potential impact of these treatments on biocomposite end-of-life has not been evaluated [31].

\subsection{Materials}

\subsubsection{Composite materials}

PHBV pellets were from TiAnan Biologic Materials Co., People's Republic of China (product code ENMAT Y1000P). The chemical formula for PHBV is $\left[\mathrm{COCH}_{2} \mathrm{CH}\left(\mathrm{CH}_{3}\right) \mathrm{O}\right]_{\mathrm{m}}\left[\mathrm{COCH}_{2} \mathrm{CH}\left(\mathrm{C}_{2} \mathrm{H}_{5}\right) \mathrm{O}\right]_{n}$, and the PHBV used in this study was $0.5 \mathrm{~mol} \% \mathrm{HV}$ content, $M_{w}=345 \mathrm{kDa}$. ENMAT Y1000P contains $1.5-2.0 \%$ additives to improve processing. Oak wood flour (OWF) was supplied by American Wood Fibers, Schofield, Wisconsin, USA under the trade name 2037-Oak. Fiber sieve analysis of the OWF confirmed that it was retained on a 20 mesh sieve, indicating a preprocessed particle 
size of greater than $841 \mu \mathrm{m}$. Volumetric analysis showed an apparent (bulk) density of $0.44 \mathrm{~g} / \mathrm{cm}^{3}$. The average aspect ratio of the preprocessed OWF was 3.6, as measured by optical microscopy [29].

\subsubsection{Positive control}

Avicel $^{\circledR}$ PH105 microcrystalline $\alpha$-cellulose was used as a positive control for $\mathrm{AD} \mathrm{CH}_{4}$ production [8]. The average particle size is $20 \mu \mathrm{m}$, with particle diameters ranging from 5 to $30 \mu \mathrm{m}$ and a length-to-width aspect ratio of 2-3 [32].

\subsubsection{Lignocellulosic components for TGA}

Cellulose: Avicel ${ }^{\circledR}$ PH105 microcrystalline $\alpha$-cellulose was used to match the cellulose component of OWF with TGA. Hemicellulose: Xylan is expected to be the main hemicellulose present in OWF [33]. Xylan, or $\operatorname{poly}(\beta$-D-xylopyranose[ $1 \rightarrow 4])$, from beechwood (TCI X0064, CAS 9014-63-5) was therefore used for TGA to match the hemicellulose component of the OWF. Lignin: Indulin AT (Westvaco, Charleston, SC) lignin was used.

\subsection{PHBV-OWF composite fabrication E treatments}

Composites studied in this work were: injection molded (1) neat PHBV, (2) maleated PHBV (mPHBV), (3) PHBV-OWF, (4) PHBV-silanated OWF (sOWF), and (5) mPHBV-OWF, with $0 \%, 20 \%$, and $40 \%$ target weight fractions of OWF. Table 1 summarizes sample nomenclature and the target and measured OWF fractions.

Processing details for these composites are provided by Srubar et al. [29], and details of the fiber treatments are provided by Wright [34]. To summarize, a subset of the OWF had silane thermochemically vapor deposited onto the particles to render the particle surfaces hydrophobic. For the maleated samples, a subset of PHBV was set aside for reactive extrusion with maleic anhydride (MA) and dicumyl peroxide. These materials were dry blended and fed through a screw extruder under $\mathrm{N}_{2}$. The grafted material was extracted to give $m P H B V$ with a graft percentage of $0.8 \%$, creating hydrophilic linkages in the grafted portions of the polymer. These processed materials were used to make master batches, via extrusion, in various fiber percentages that were then used in injection molding. Rectangular prisms, $31.25 \mathrm{~mm} \times 6.2 \mathrm{~mm} \times 2.1 \mathrm{~mm}$ in dimension, were used for the biodegradation experiments.

\subsection{Materials characterization}

The composition of representative composites from each of the sample batches, shown in Table 1, was analyzed by measuring fiber fraction and COD. COD was measured for the fiber, neat bioplastic, and the composites. Differential scanning calorimetry (DSC) was used to gain insight into the biocomposite structure.

\subsubsection{Fiber fraction}

The weight percent of fiber filler for the PHBV-OWF composites was determined according to Section 2.1.1: the composite samples were weighed, the PHBV matrix was dissolved in chloroform, and the OWF was collected, dried, and weighed. The insolubility of the OWF in chloroform was verified by weighing a known amount of OWF and performing the above steps.

\subsubsection{Stoichiometry of components with known composition}

Eq. (2) was used to predict the $\mathrm{ThCH}_{4}$ for PHBV and cellulose. For PHBV with $5 \mathrm{~mol}$.\% hydroxyvalerate (HV) the maximum theoretical volume of $\mathrm{CH}_{4}$ that would be produced is $672 \mathrm{~mL} \mathrm{CH}_{4}$ per $\mathrm{g}$ PHBV at $37^{\circ} \mathrm{C}$. Composition of the gas in the headspace can also be predicted using this Eq. (2). For cellulose, the expected gas composition is $50 \% \mathrm{CH}_{4}$ and $50 \% \mathrm{CO}_{2}$. For PHBV ( $5 \mathrm{~mol} . \% \mathrm{HV}$ ), the gas composition is $56 \% \mathrm{CH}_{4}$ and $44 \% \mathrm{CO}_{2}$.

\subsubsection{Stoichiometry of components with unknown composition}

The theoretical biodegradability of the lignocellulosic component of biocomposites, in this case OWF, cannot be easily defined using Eq. (2) due to the complicated structure of lignocellulose, which frequently lacks a well-defined chemical stoichiometry. The organic content, as determined by COD, of (i) injection molded PHBV and representative PHBV-OWF composites, (ii) PHBV powder and pellets, (iii) OWF, and (iv) the cellulose control (Avicel ${ }^{\circledR}$ PH105) was measured using the assay from Section 2.1.3: slices of PHBV pellets and slices of PHBV-OWF composites were cut, weighed, and added to COD vials along with $2 \mathrm{~mL}$ of DI water to obtain the appropriate dilution. The PHBV powder, OWF, and cellulose were weighed out and added to the COD vial along with $2 \mathrm{~mL}$ of DI water.

Measured values for PHBV and cellulose were compared to the COD (ThCOD) as calculated from the chemical formulae and the oxidation reaction for non-nitrogen-containing organics:

$\mathrm{C}_{n} \mathrm{H}_{a} \mathrm{O}_{b}+\left(n+\frac{a}{4}-\frac{b}{2}\right) \mathrm{O}_{2} \longrightarrow n \mathrm{CO}_{2}+\frac{a}{2} \mathrm{H}_{2} \mathrm{O}$

The COD values for PHBV, $2 \%$ maleated PHBV (2mPHBV), and OWF, multiplied by weight fraction data for the composites, were used to calculate COD values for the composites. These values were compared to measured COD values. Calculated and measured values were in good agreement. Accordingly, calculated values were used to determine $\mathrm{ThCH}_{4}$, which was then used to calculate biodegradability for composite samples as discussed in Section 2.4.

\subsubsection{Additional analysis: DSC}

A TA Instruments Q2000 DSC with a nitrogen flow rate of $50 \mathrm{~mL} / \mathrm{min}$ was used to analyze the bioplastic and composites. Samples were encapsulated in aluminum pans with a target sample weight of $5 \mathrm{mg} \pm 2 \mathrm{mg}$, and heated from $-40{ }^{\circ} \mathrm{C}$ to $180^{\circ} \mathrm{C}$ in the first heating cycle at a rate of $10^{\circ} \mathrm{C} / \mathrm{min}$. After equilibrating to $180^{\circ} \mathrm{C}$, they were held at $180^{\circ} \mathrm{C}$ for 2 min prior to cooling at

Table 1

PHBV-OWF composites with treatments: sample nomenclature and targeted and measured formulation [29]. Maleated composites contained $2 m$ PHBV.

\begin{tabular}{|c|c|c|c|c|c|c|}
\hline \multirow[t]{2}{*}{ Sample } & \multicolumn{4}{|c|}{ Target wt.\% } & \multicolumn{2}{|c|}{ Measured wt.\% } \\
\hline & PHBV & $m$ PHBV & OWF & sOWF & OWF & sOWF \\
\hline $\mathrm{P}$ & 100.0 & 0 & 0 & 0 & 0 & 0 \\
\hline P20 & 80.0 & 0 & 20 & 0 & 20.3 & 0 \\
\hline P40 & 60.0 & 0 & 40 & 0 & 40.2 & 0 \\
\hline P20S & 80.0 & 0 & 0 & 20 & 0 & 22.2 \\
\hline P40S & 60.0 & 0 & 0 & 40 & 0 & 52.0 \\
\hline $2 \mathrm{M}$ & 98.0 & 2.0 & 0 & 0 & 0 & 0 \\
\hline 2M20 & 78.4 & 1.6 & 20 & 0 & 20.3 & 0 \\
\hline $2 \mathrm{M} 40$ & 58.8 & 1.2 & 40 & 0 & 45.8 & 0 \\
\hline
\end{tabular}


$10^{\circ} \mathrm{C} / \mathrm{min}$ to $-40^{\circ} \mathrm{C}$. The samples were then heated at $10^{\circ} \mathrm{C} / \mathrm{min}$ to $200{ }^{\circ} \mathrm{C}$ in the second and final heating cycle. This procedure was chosen to avoid thermal degradation in the first cycle, but allow for accurate melting peak area determination in the second cycle. The reported thermal transitions were taken from the second heating cycle. The glass transition temperature $\left(T_{g}\right)$ was taken to be the midpoint of the heat capacity change, the melting temperature $\left(T_{m}\right)$ was measured as the minimum of the endothermic peak, and the crystallization temperature $\left(T_{c}\right)$ was taken as the maximum temperature of the exothermic peak upon cooling (in between the first and second cycles). These measurements were performed at the Soft and Hybrid Materials Facility (SMF) at Stanford University.

The percent crystallinity of the PHBV matrix, $\chi$, in bioplastics and biocomposites representative of those tested for anaerobic degradation was determined using the following equation [35]:

$\chi[\%]=\frac{\Delta H_{m}-\Delta H_{c}}{\Delta H_{m}^{\circ}\left(1-W_{f}\right)} \cdot 100 \%$

where $\Delta H_{m}$ and $\Delta H_{c}$ are the enthalpies of melting and crystallization measured upon heating, $W_{f}$ corrects for the fiber content of the composite, and $\Delta H_{m}^{0}$ is the reference value for $100 \%$ crystalline $\mathrm{PHB}, 146 \mathrm{~J} / \mathrm{g}$ or $12.5 \mathrm{~kJ} / \mathrm{mole}$ [36,37]. As a reference, a typical value for the crystallinity of annealed PHB samples measured by Barham et al. was $86 \%$ [36].

\subsection{Methane production assay}

Because of limitations on the number of samples that could be analyzed using the volumetric methane measurement system (see Section 2.2.4), samples tested for $\mathrm{CH}_{4}$ production (Fig. 1) were
Table 2

Sample types measured for $\mathrm{CH}_{4}$ production in each test group.

\begin{tabular}{llll}
\hline Sample type & ID & Grp1 & Grp2 \\
\hline PHBV & P & $2 \mathrm{x}$ & $2 \mathrm{x}$ \\
PHBV-20\%OWF & P20 & $2 \mathrm{x}$ & $2 \mathrm{x}$ \\
PHBV-40\%OWF & P40 & $2 \mathrm{x}$ & $2 \mathrm{x}$ \\
$2 m$ PHBV & $2 \mathrm{M}$ & $2 \mathrm{x}$ & \\
$2 m$ PHBV-20\%OWF & $2 \mathrm{M} 20$ & $2 \mathrm{x}$ & \\
$2 m$ PHBV-40\%OWF & $2 \mathrm{M} 40$ & & $2 \mathrm{x}$ \\
PHBV-20\%sOWF & P20S & & $2 \mathrm{x}$ \\
PHBV-40\%SOWF & P40S & & $2 \mathrm{x}$ \\
\hline
\end{tabular}

divided into two test groups and analyzed in duplicate (Table 2). For each group, negative controls (i.e., anaerobic digester inoculum only) were analyzed in triplicate. The cellulose used as a positive control was considered to have fully biodegraded at $80 \%$ or greater of $\mathrm{ThCH}_{4}$ (Eq. (4)) [38]. The masses of test samples and positive controls were adjusted to ensure consistent addition of COD for all bioreactors, with composite test samples added at $\sim 0.5 \mathrm{~g}$ and microcrystalline cellulose added at $0.68 \mathrm{~g}$.

\subsubsection{Sample preparation}

Prior to anaerobic biodegradation testing, all samples were dried in a vacuum desiccator for 1 week then weighed. To facilitate measurements of sample mass loss at the end of the experiment, samples were placed in retrievable bags made from Spectra/Mesh polypropylene filters with a mesh opening of $297 \mu \mathrm{m}$ and $36 \%$ open area. As the pre-processed OWFparticle size is $>841 \mu \mathrm{m}$ [29], this size was selected to retain un-degraded OWF while allowing sufficient access to the samples by microorganisms in the medium. In order to control for any experimental variability
$\mathbf{P}$

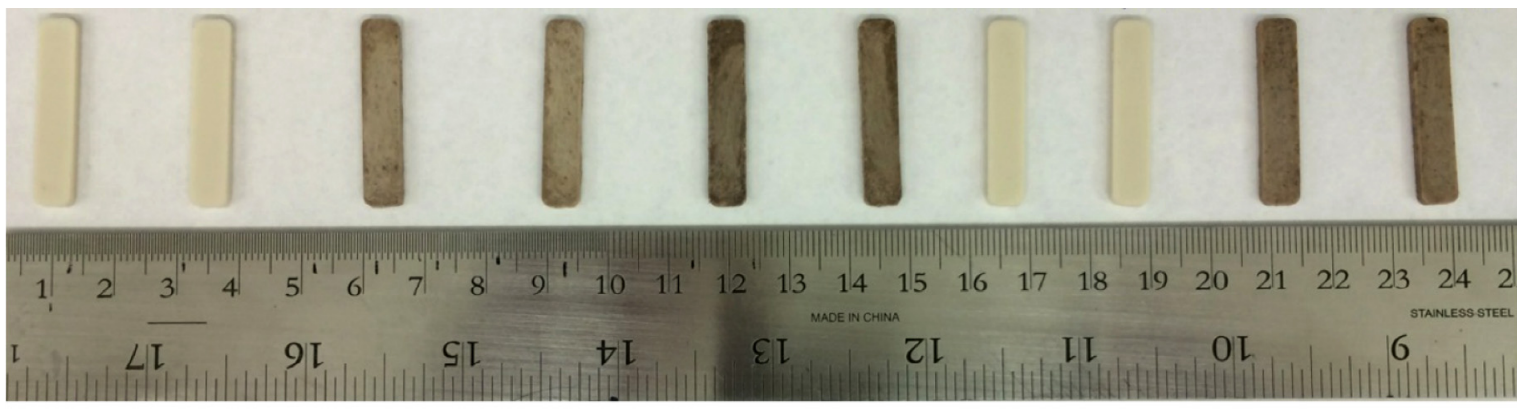

(a)Group1
$\mathbf{P}$

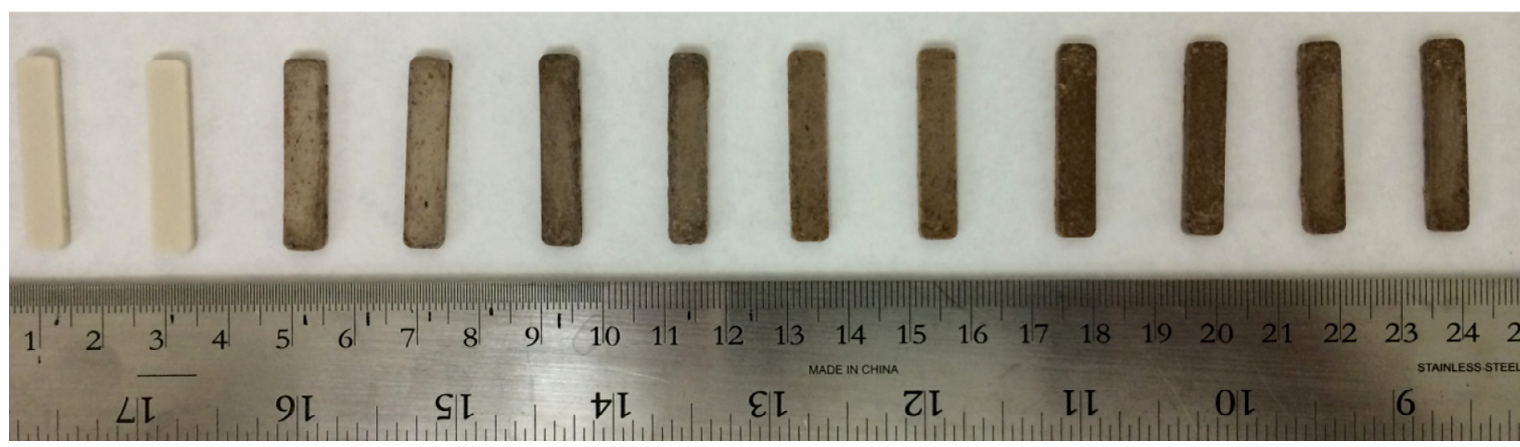

(b)Group2

Fig. 1. PHBV-OWF composite samples measured for biogas production (in duplicate). Sample key is provided in Table 2. 
that could be introduced from the mesh bags, the bags were also included in the control vessels.

\subsubsection{Preparation of anaerobic media and inoculum}

Anaerobic media was prepared according to Section 2.2.3. Inocula for all experiments were collected from the anaerobic digesters at the San Jose Waste Water Treatment Plant in 4-L sample containers. As mentioned above, because of limitations in the number of samples that could be analyzed for biogas volume in each experiment, the samples were divided into two experimental groups. The analysis for the anaerobic digester sludge and the mineral media mixed with inoculum for each experimental group is provided in the supplementary material. COD, pH, SS, VSS, and alkalinity were measured as per Standard Methods for the Examination of Water and Wastewater [15]. All samples were measured in duplicate. For the media plus inoculum samples taken while filling the sample reactors, a sample was taken prior to filling and postfilling in order to ensure uniformity in the biosolids and media added to all reactors.

\subsubsection{Automated methane test setup}

Samples were added to bioreactors following the methodology described in Section 2.2.4, and connected to the AMPTSII, which was enabled for overhead mixing. Stir speed was set to $50 \mathrm{rpm}$, and the reactor vessels were mixed in 4-h cycles, with $30 \mathrm{~min}$ of mixing followed by $330 \mathrm{~min}$ of quiescence. These parameters were selected based on prior work indicating that aggressive mixing may inhibit microbial adhesion to the composites $[39,40]$.

\subsubsection{Biogas composition}

Samples analyzed for biogas composition were collected using a $1 \mathrm{~mL}$ gas tight syringe (VICI, Pressure Lok ${ }^{\circledR}$ Series A-2 syringe, Product No. 050033) with a sideport gas sampling needle (VICI, Product No. 943052). $\mathrm{CH}_{4}, \mathrm{CO}_{2}$, and nitrogen $\left(\mathrm{N}_{2}\right)$ were measured in the headspace using GC on a Gow-Mac 580 Series gas chromatograph equipped with a thermal conductivity detector (TCD). The gasses were separated at $45^{\circ} \mathrm{C}$ on a $8^{\prime} \times 1 / 8^{\prime \prime}$ HayeSep $\mathrm{Q}$ $80 / 100$ mesh micropacked column. Helium $(\mathrm{He})$ was used as a carrier gas at a flow rate of $30 \mathrm{~mL} / \mathrm{min}$. The temperature of the injector and detector was kept at $120^{\circ} \mathrm{C}$. The volume collected of all samples and standards was $0.6 \mathrm{~mL}$. Prior to injection, the gas in the syringe was compressed to the $0.5 \mathrm{~mL}$ injection volume and rapidly equilibrated with atmospheric pressure by toggling the valve on the syringe. The sample was then immediately injected into the GC sampling port. The standard run time was 4 min. Calibration standards were developed by blending known concentrations of $\mathrm{CH}_{4}, \mathrm{CO}_{2}, \mathrm{~N}_{2}$, and He over the measurement range of interest. Standards were analyzed each run.

\subsection{Modeling of assay results}

Matlab 2015b was used to process raw $\mathrm{CH}_{4}$ data by applying channel calibrations, normalizing to sample mass, and converting measured gas volumes at room temperature and pressure to $37^{\circ} \mathrm{C}$. A lookup table of negative control gas volumes was used to accurately subtract out the negative control data from the $\mathrm{CH}_{4}$ produced by the positive control and test samples. Normalized data were fit to the Gompertz model (Eq. (3)) using the Curve Fitting application in Matlab 2015b, with non linear least squares and the Trust-Region algorithm. Upper and lower 95\% confidence and prediction intervals and goodness of fit $\left(R^{2}\right)$ were calculated for all fit parameters. These fit parameters were used with the Curve Fitting Analysis in IgorPro 6.37 to further analyze and plot the data.

\subsection{Calculation of biodegradability}

\subsubsection{Percent biodegradability}

Percent biodegradability was computed as per Eq. (4). For neat and maleated PHBV, $\mathrm{ThCH}_{4}$ was calculated using Eq. (2). For the composites, the calculated values of COD from Table 3 were used to determine $\mathrm{ThCH}_{4}$ at $37^{\circ} \mathrm{C}$. Overall bioplastic and composite biodegradability was calculated using the $P_{m}$ parameter in the Gompertz model fit for $\mathrm{CH}_{4}$ production, Eq. (3). The biodegradability of the lignocellulosic components of was further assessed using thermogravimetric analysis (TGA) (Section 3.6.3).

\subsubsection{Biodegradation of fibers}

The remaining mass of bioplastic and biocomposite samples was collected and dried post-degradation. The biodegradation of the fiber component of the composites was calculated in two ways. The first was by mass loss:

$\%$ Mass $=\frac{\left(W_{f} \cdot M_{I, c}\right)-M_{F}}{W_{f} \cdot M_{I, c}} \times 100 \%$

where $W_{f}$ is the fiber fraction of the composite, $M_{I, c}$ is the initial mass of the composite, and $M_{F}$ is the final mass collected after degradation (assuming complete biodegradation of the PHBV, based on experimental observation).

Table 3

Calculated and measured values of $\mathrm{COD}$ and $\mathrm{ThCH}_{4}$ for individual materials: PHBV, cellulose, and OWF and injection molded bioplastics and biocomposites.

\begin{tabular}{|c|c|c|c|}
\hline Individual materials & $\begin{array}{l}\text { Calculated ThCOD }^{\mathrm{a}} \\
\text { [g COD/g material] }\end{array}$ & $\begin{array}{l}\text { Measured } \text { COD }^{\mathrm{c}} \\
{[\mathrm{g} \text { COD/g material] }}\end{array}$ & $\begin{array}{l}\mathrm{ThCH}_{4}, 37^{\circ} \mathrm{C}^{\mathrm{a}} \\
{[\mathrm{mL} / \mathrm{g}]}\end{array}$ \\
\hline PHBV pellet & 1.69 & $1.75 \pm 0.01$ & 672 \\
\hline PHBV powder & 1.69 & $1.75 \pm 0.02$ & 672 \\
\hline OWF & - & $1.18 \pm 0.22$ & 470 \\
\hline $\begin{array}{l}\text { Avicel }{ }^{\circledR} \text { PH105 } \\
\quad \text { (Microcrystalline Cellulose) }\end{array}$ & 1.19 & $1.14 \pm 0.02$ & 473 \\
\hline Injection molded samples & $\begin{array}{l}\text { Calculated ThCOD }^{\mathrm{b}} \\
\text { [g COD/g material] }\end{array}$ & $\begin{array}{l}\text { Measured } \mathrm{COD}^{\mathrm{c}} \\
{[\mathrm{g} \mathrm{COD} / \mathrm{g} \text { material] }}\end{array}$ & $\mathrm{ThCH}_{4}, 37^{\circ} \mathrm{C}^{\mathrm{b}}[\mathrm{mL} / \mathrm{g}]$ \\
\hline PHBV (bioplastic) & 1.75 & $1.74 \pm 0.01$ & 697 \\
\hline $2 m$ PHBV (bioplastic) & 1.75 & $1.72 \pm 0.02$ & 697 \\
\hline P20 (biocomposite) & 1.63 & $1.64 \pm 0.08$ & 649 \\
\hline P40 (biocomposite) & 1.52 & $1.51 \pm 0.02$ & 605 \\
\hline 2M20 (biocomposite) & 1.62 & $1.62 \pm 0.01$ & 645 \\
\hline
\end{tabular}

a ThCOD and $\mathrm{ThCH}_{4}$ based on stoichiometry (Buswell and Mueller, Eq. (2)). The $\mathrm{ThCH}_{4}$ value for OWF is taken from the measured COD value.

b $\mathrm{ThCOD}$ and $\mathrm{ThCH}_{4}$ is calculated from measured COD values for the PHBV pellet and OWF, and the measured OWF wt.\% as given in Table 1. ThCOD for the 2M20 samples was calculated using the measured $2 \mathrm{mPHBV}$ value for COD.

c Average of 3 samples. 
The second method investigated $\mathrm{CH}_{4}$ production from the fiber component. Any excess $\mathrm{CH}_{4}\left(V_{\mathrm{CH}_{4} \text {,excess }}\right)$ above what is expected for degradation of the PHBV component $\left(V_{\mathrm{CH}_{4} \text { expected }}\right)$ is attributed to degradation of the fibers:

$V_{\mathrm{CH}_{4}, \text { excess }}=V_{\mathrm{CH}_{4} \text {, measured }}-V_{\mathrm{CH}_{4} \text {,expected }}$

where $V_{\mathrm{CH}_{4} \text { expected }}=B_{\mathrm{PHBV}} \cdot \mathrm{ThCH}_{4, \mathrm{PHBV}}, \mathrm{B}_{\mathrm{PHBV}}$ is the biodegradability of the neat PHBV reference samples from $P_{m}$ and Eq. (4), and $\mathrm{ThCH}_{4, \mathrm{PHBV}}$ is calculated for the PHBV component of the biocomposite $\left(M_{P H B V}=\left(1-W_{f}\right) \cdot M_{I, C}\right)$.

Table 4

Thermal properties and crystallinity of PHBV-OWF composites measured for biodegradation.

\begin{tabular}{lccc}
\hline Sample & $T_{m}\left[{ }^{\circ} \mathrm{C}\right]$ & $\Delta H_{m}[\mathrm{~J} / \mathrm{g}]$ & $\chi[\%]$ \\
\hline P & 173.3 & 90.0 & 61.6 \\
P20 & 171.9 & 71.9 & 61.8 \\
P40 & 170.1 & 51.8 & 59.4 \\
P20S & 173.4 & 68.8 & 60.5 \\
P40S & 170.3 & 47.4 & 67.7 \\
2M & 172.9 & 82.8 & 56.7 \\
2M20 & 172.1 & 73.4 & 63.1 \\
2M40 & 170.6 & 51.1 & 64.6 \\
\hline
\end{tabular}

\subsubsection{Thermogravimetric analysis (TGA) of wood fiber}

Sub-components that are commonly measured and reported for lignocellulosic biomass are: hemicellulose, cellulose, lignin, and on occasion holocellulose, the carbohydrate (hemicellulose plus $\alpha$-cellulose) content $[41,42]$. Thermogravimetric analysis (TGA) is a promising and increasingly well established technique for analysis of cellulose, hemicellulose, and lignin [43,44,42] and has been used to characterize the stability of the WF component in nonbiodegradable wood-plastic composites (WPCs) [45,46]. Analyzing relative ratios of such sub-components in the WF before and after anaerobic degradation can help to establish the bio-availability of these components and assist in predicting of overall composite $\mathrm{CH}_{4}$ production.

After $\mathrm{CH}_{4}$ production had plateaued, undegraded OWF was left in the mesh sample bags. This material was dried for 2 weeks in a vacuum desiccator and weighed. TGA (TA Q500) was used to characterize the lignocellulosic components of the WF before and after degradation. A mass of 10-15 mg was used for both powder lignocellulose standards and fiber samples. The experiments were per-

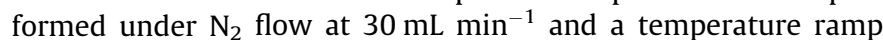
of $5{ }^{\circ} \mathrm{C} \mathrm{min}-1$ from room temperature to $700^{\circ} \mathrm{C}$, followed by a dwell at $700{ }^{\circ} \mathrm{C}$ for $30 \mathrm{~min}$. Mass loss and heating rate were recorded.

Single component and mixed standards were made from xylan, cellulose, and lignin by weighing out and blending powders of the

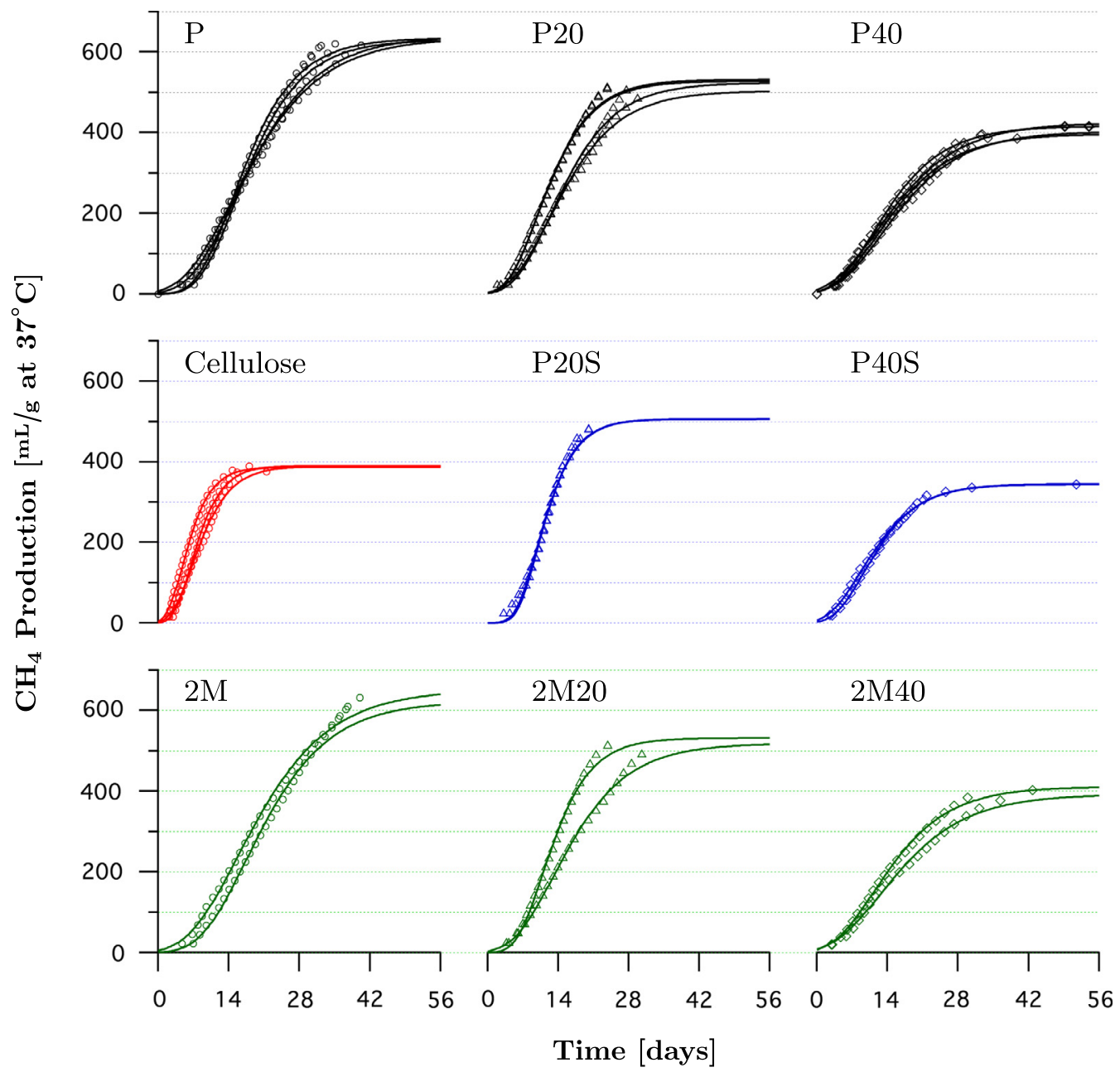

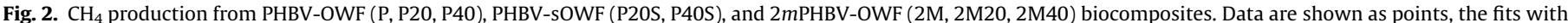

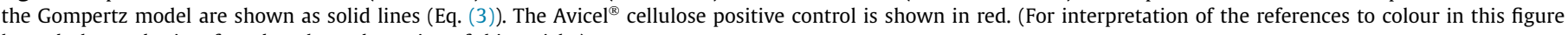
legend, the reader is referred to the web version of this article.) 
different components in xylan:cellulose:lignin ratios of 100:0:0, $0: 100: 0,0: 0: 100,25: 40: 25$, and 33:33:33. These standards were used to evaluate the peak locations for the derivative of weight loss, as well as calculate component amounts. In order to quantify the contribution of the individual components to the weight loss, multi-peak fitting of the three components was done in IGOR Pro.

\section{Results and discussion}

\subsection{Composite characterization}

\subsubsection{Fiber fraction}

The results for fiber weight fraction, $W_{f}$, are shown as the measured values in Table 1 . Measured $W_{f}$ deviates from the target values minimally at $20 \%$ OWF and more significantly at $40 \%$ OWF. This variation was due to the difficulties in precisely metering material feed rates during the master batch blending and extrusion process, and precluded direct comparisons in composites with $40 \%$ target OWF. Even with this variability, trends in lag time, rate, and overall $\mathrm{CH}_{4}$ production were observed.

\subsubsection{Chemical oxygen demand}

Table 3 summarizes measured COD values for the composite constituents. Close agreement was observed between calculated (predicted) values and measured values for COD of the individual materials. However, the measured value for the PHBV pellets and powder was slightly higher than expected. The manufacturer indicated that there were additives in the PHBV to facilitate processing. The presence of these additives may account for some of the COD deviation observed. COD values were used to calculate the expected $\mathrm{ThCH}_{4}$ for both the injection molded bioplastics and the biocomposites, so accurate values are important for biodegradability assessments. The measured PHBV pellet value was therefore used to calculate ThCOD for the biocomposites.

From the COD values measured in the top half of Table 3, and the weight fraction data shown in Table 1, the COD of the injection molded bioplastics and biocomposites was calculated and is shown in the bottom half of Table 3 alongside the measured COD values for these materials. There was close agreement observed between expected and measured values of COD for the bioplastics and biocomposites. The calculated values were therefore used to determine the $\mathrm{ThCH}_{4}$ for the composite samples.

\subsubsection{PHBV matrix crystallinity}

Table 4 shows theDSC data for the temperature $\left(T_{m}\right)$ and enthalpy $\left(\Delta H_{m}\right)$ of melting for the biocomposites as well as the crystallinity of the PHBV matrix adjusted for $W_{f}(\chi)$. As observed in Srubar et al. [29], $T_{m}$ decreased with increasing OWF content. Crystallinity did not vary significantly between the neat bioplastic and untreated composite samples, however there was a trend toward higher crystallinity in the treated composites with high $W_{f}$ of WF. Other studies of WPCs have observed increases in matrix crystallinity with the addition of WF, attributed to WF acting as a nucleating agent for crystallization [47]. The use of coupling agents, such as the compatibilization treatments used in this study, has similarly been observed to make WF more effective in this capacity [48]. While previous observations have correlated degree of crystallinity and lamellar thickness to enzymatic degradation rates of PHBV [49], the range in $\chi$ observed in these samples was not found to have a statistically significant effect on lag time to initiation of degradation or on maximum $\mathrm{CH}_{4}$ production rate.

\subsection{Methane production data and modeling}

\subsubsection{Methane production model fit and parameters}

Fig. 2 shows the normalized $\mathrm{CH}_{4}$ production versus degradation time for the composite samples, along with a fit to the Gompertz growth model. This model described the data well with goodness-of-fit $\left(R^{2}\right)$ values greater than 0.995 . The methane production potential per unit weight of the composite, $P_{m}[\mathrm{~mL} / \mathrm{g}]$, can be seen as the ultimate value of $\mathrm{CH}_{4}$ generated in a sample at the end of the experiment (the plateau). The lag phase time, $\lambda$ [days], is apparent at the beginning of the experiment, and corresponds to the initial colonization of microorganisms and initiation of degradation. The specific methane production rate, $R$ [ $\mathrm{mL} / \mathrm{g}$ day], corresponds to the rate at the midpoint of the $\mathrm{CH}_{4}$ generation curve.

Fig. 3 shows the model parameters, $P_{m}, R$, and $\lambda$, versus increasing OWF content. Where appropriate, a linear fit was applied to the observed trends. Untreated samples are shown in black, maleated samples in green, and silane-treated samples in blue in the plots. Total production potential $\left(P_{m}\right)$ and lag time $(\lambda)$ have a clear, statistically significant, linear dependence on OWF content; the $95 \%$ confidence interval for the slopes of both of the linear fits gives $p<0.05$. However, the relationship between OWF\% and maximum production rate $(R)$ is not linear. The silane-treated samples have a higher rate than the maleated and untreated composites at both $20 \%$ and $40 \%$ OWF. This variability of production rate versus OWF content of the neat, maleated, and silane-treated samples is readily seen in the vertical spread of data, particularly at 20\% OWF (highlighted by the red selection in Fig. 3).

Plotting the parameters extracted from the Gompertz model versus OWF content of the composites yields insights into composite degradation. The lag time of $\mathrm{CH}_{4}$ production, $\lambda$, was affected by the OWF content in both the neat and treated composites: lag time
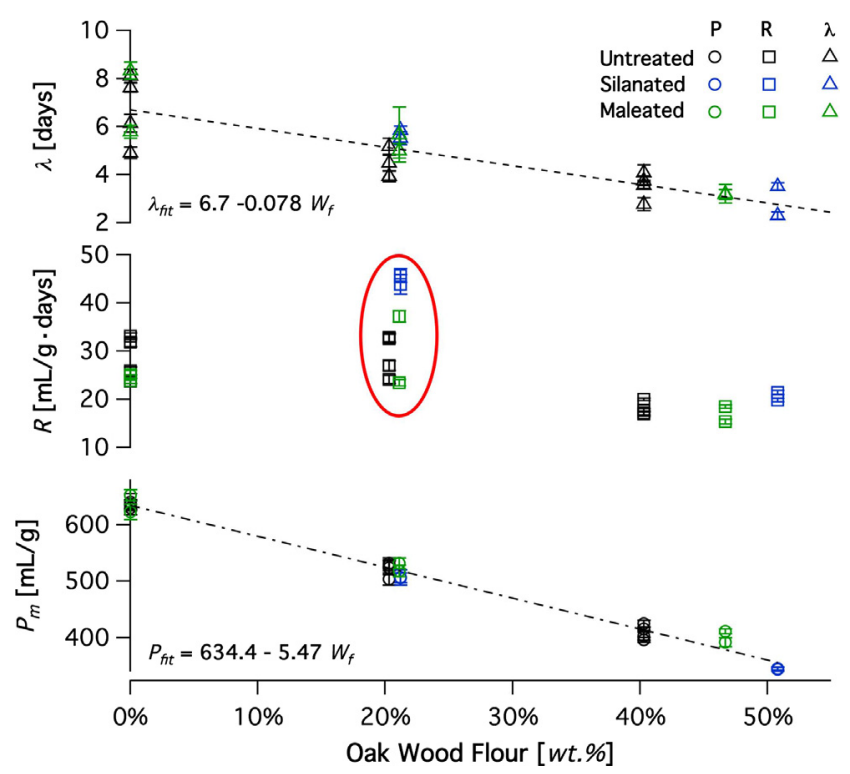

Fig. 3. Gompertz growth model parameters for biocomposite methane production versus OWF content. $P_{m}=\mathrm{CH}_{4}$ production potential, $R=\max$ rate, and $\lambda=\operatorname{lag}$ time. Error bars on the data show the $95 \%$ confidence intervals for the parameter fits in the Gompertz model. The linear fit for $\lambda, \lambda_{\text {fit }}=m_{1} \cdot\left(W_{f} \times 100 \%\right)+b_{1}$ has a $95 \%$ confidence interval for the parameters: $m_{1}=-0.078 \pm 0.022$ and $b_{1}=6.70 \pm 0.66$. The linear fit for $P_{m}, P_{f i t}=m_{2} \cdot\left(W_{f} \times 100 \%\right)+b_{2}$ has a $95 \%$ confidence interval for the parameters: $m_{2}=-5.47 \pm 0.33$ and $b_{2}=634.4 \pm 9.7$. The $p$-value for the slopes in both cases is $<0.05$. The red oval highlights the differences in maximum rate between the different treatments at $20 \%$ OWF. (For interpretation of the references to colour in this figure legend, the reader is referred to the web version of this article.) 
decreased with increasing OWF content. However, no significant difference between treated and untreated or treatment types was observed. As discussed by Ryan [6], fibers introduce additional surface area and accelerated initial hydrolysis is likely due to additional pathways for ingress of water, microorganisms, and enzymes into the composite samples. The inverse linear relationship between ultimate $\mathrm{CH}_{4}$ production, $P_{m}$, and OWF content is not affected by these treatments, indicating that the maleation and silanation treatments do not inhibit anaerobic biodegradation.

The maximum rate of degradation, $R$, increased slightly at $20 \%$ OWF in the untreated and maleated composites, but at $40 \% \mathrm{OWF}$, the rate decreased. With the increased surface area and statistically insignificant effect of crystallinity at the higher OWF content composites, the observed rate decrease at $40 \% \mathrm{OWF}$ was unexpected. It may be that above a certain volume of fiber, there is enough interconnected volume of OWF in the polymer matrix that fragmentation of material begins to impact the colonization of the microorganisms on, and enzymatic interaction with, the undegraded substrates $[6,50]$. Silane treatment increased the rate in both the P20S and P40S samples as compared to the P20, P40, $2 \mathrm{M} 20$, and 2M40 composites, but like the other composites, the observed rate decreased as fiber fraction increased between $20 \%$ and $40 \%$ target fiber fractions. This increase in rate in the P20S composites is likely due to increased moisture-induced damage as observed by Srubar et al. and Ryan [51,6].

\subsubsection{Headspace gas composition}

Fig. 4 shows the gas composition as measured from the gas sampling "T's" situated inline close to the reactor headspace over the course of the experiment. $\mathrm{CH}_{4}$ fraction is shown as the solid lines, and $\mathrm{CO}_{2}$ fraction is the dashed lines. The positive control samples (cellulose) are expected to have a $\mathrm{CH}_{4}$ percentage around $50 \%$, and the PHBV composites are expected to have a percentage around $56 \%$. The measured values were higher, but these values align with other studies using similar media [10,39] and can be attributed to the increased solubility of $\mathrm{CO}_{2}$ in the liquid phase as compared to $\mathrm{CH}_{4}$. The data show that there is no significant difference in headspace gas composition, as would be expected with primarily the PHBV fraction of the composites degrading.

\subsection{Biodegradation}

\subsubsection{Percent biodegradability}

Comparing the measured $\mathrm{CH}_{4}$ production to the theoretical $\mathrm{CH}_{4}$ production for the composite samples yields a decreasing linear trend in biodegradability with increasing OWF\%, as is shown in Fig. 5a. Fig. 5b shows the biodegradability of the composites by composite type.

The microcrystalline cellulose controls degraded just over $80 \%$ of the theoretical value for cellulose, indicating a valid positive control. PHBV and $2 \mathrm{mPHBV}$ both reached $83 \%$ of the theoretical
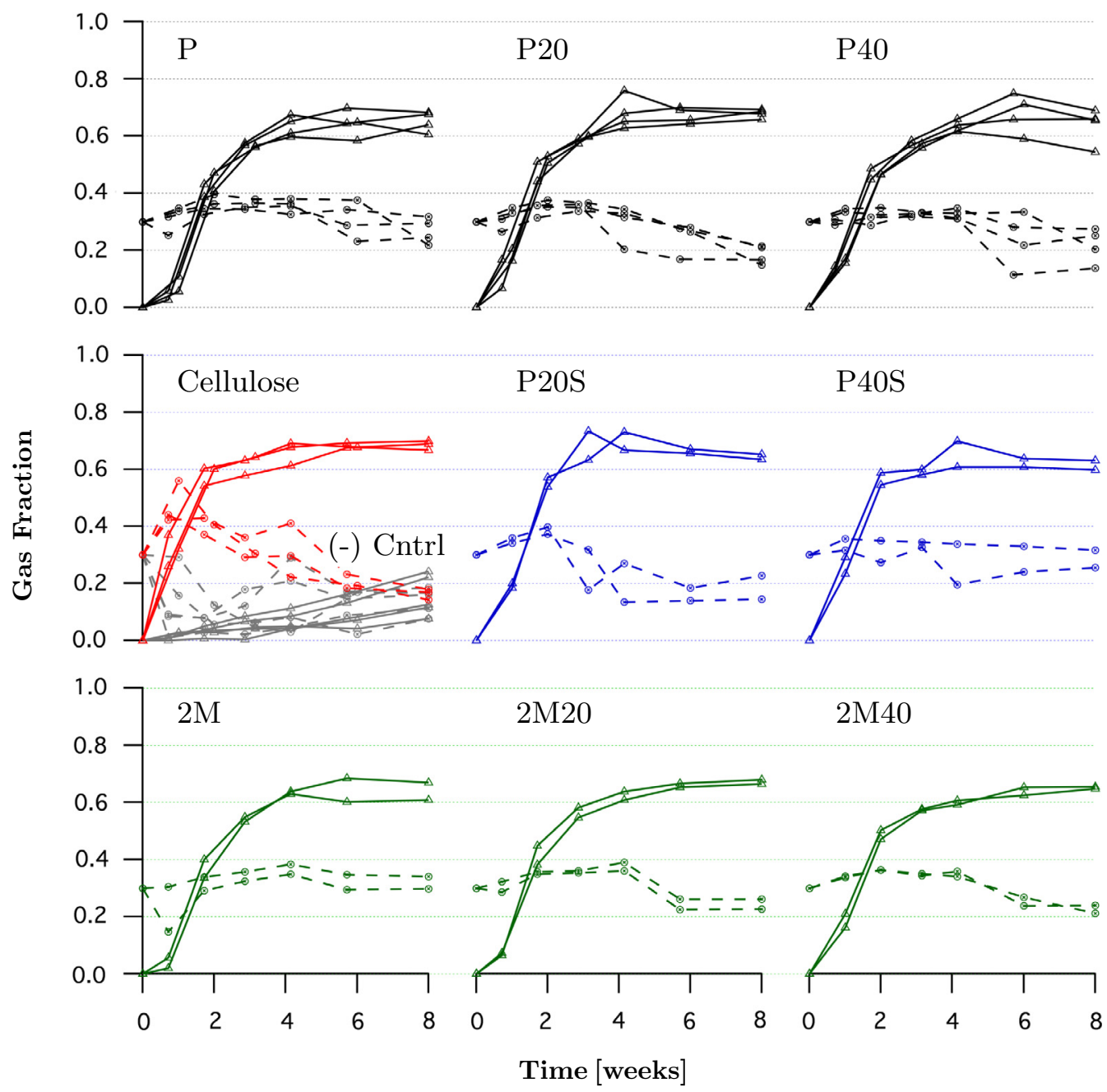

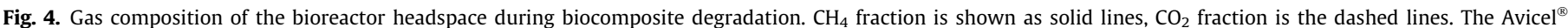

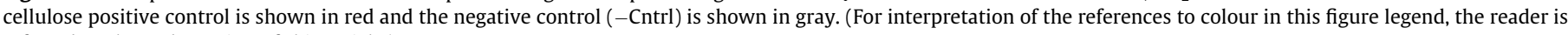
referred to the web version of this article.) 

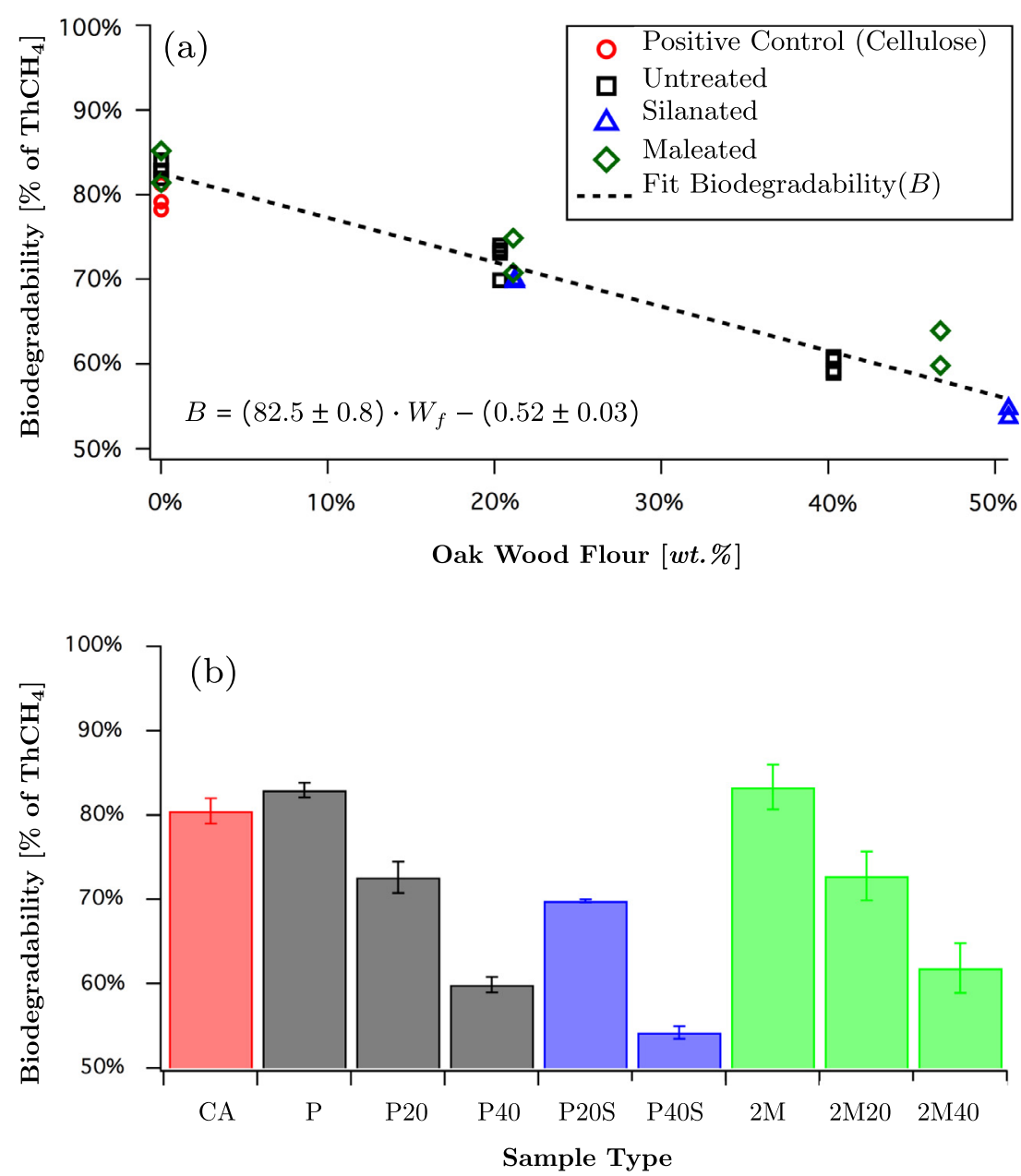

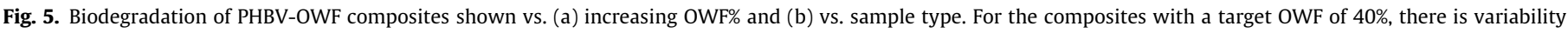

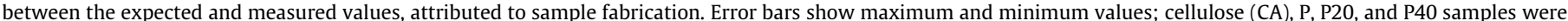

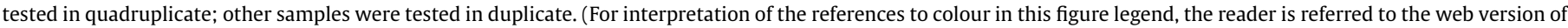
this article.)

Table 5

Percentage of OWF weight loss and excess $\mathrm{CH}_{4}$ due to fiber degradation by treatment condition.

\begin{tabular}{ccc}
\hline Treatment type & \multicolumn{2}{c}{ Degradation of oak wood flour ${ }^{\mathrm{a}}$} \\
\cline { 2 - 3 } & Weight loss [\%] & ${\text { Excess } \mathrm{CH}_{4}[\mathrm{~mL} / \mathrm{g}]}$ \\
\hline Untreated & $38 \pm 11$ & $26 \pm 14$ \\
Silanated & $52 \pm 4$ & $45 \pm 24$ \\
Maleated & $39 \pm 12$ & $22 \pm 14$ \\
\hline
\end{tabular}

a Average of $20 \%$ and $40 \%$ samples for each sample type \pm one standard deviation.

value, with slightly more variability in the maleated samples (PHBV: $\quad 83.1 \pm 0.5 \%, \quad 2 m$ PHBV: $83.0 \pm 1.8 \%$ ). The ultimate biodegradability of the PHBV samples was greater than $80 \%$, indicating that these samples can also be considered fully biodegradable, which was expected as there have been previous studies on the anaerobic degradation of PHBV in simulated landfill environments $[52-55,25,56]$. The samples in this study are larger than typically evaluated, however, so it was important to confirm complete biodegradation and to provide a reference for the composite samples. The $2 m$ PHBV samples also fully degraded, indicating that maleation did not negatively impact the biodegradability of the bioplastic.

As expected, the composite samples did not fully biodegrade in the time frame of these experiments. The P20, P20S, and 2M20

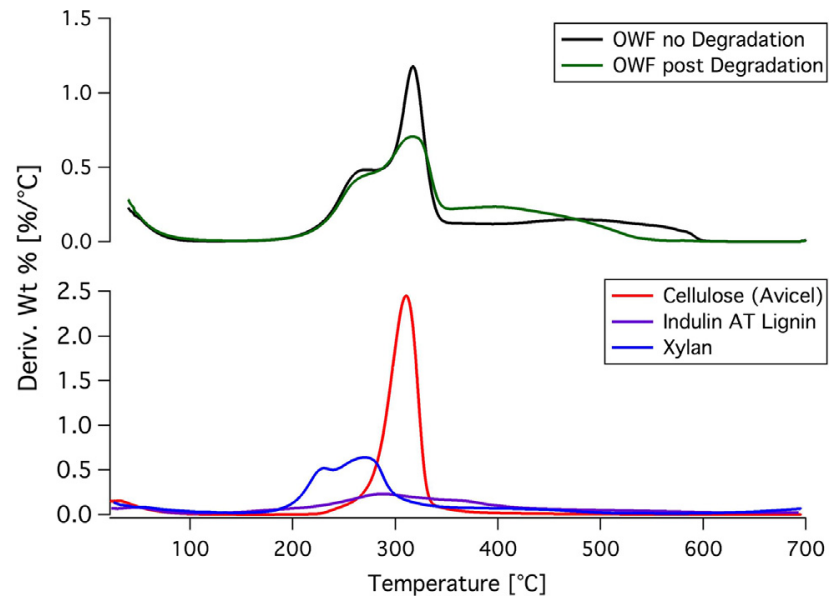

Fig. 6. TGA derivative weight $\%$ of $\mathrm{OWF}$ with no degradation and after anaerobic degradation in the biocomposites, P20 sample is shown (top). (Bottom) an overlay of derivative weight \% for the major components of OWF: cellulose, lignin, and xylan. (For interpretation of the references to colour in this figure legend, the reader is referred to the web version of this article.)

samples reached $73 \%, 70 \%$, and $73 \%$ respectively. The $\mathrm{P} 40, \mathrm{P} 40 \mathrm{~S}$, and 2 M40 samples reached $60 \%, 54 \%$, and $62 \%$. This variability 
between composite sample types is due to the differences between the target and actual OWF content of each of the different sample types (Table 1). Research on the anaerobic degradation of various lignocellulosic materials, including hardwoods, reports degradation of the cellulosic fraction and very slow degradation of lignin [57]. The contribution of the OWF to biogas production is discussed in Section 4.3.2.

\subsubsection{Degradation of the fiber}

Table 5 summarizes the average OWF mass loss and excess $\mathrm{CH}_{4}$ production attributed to the fiber fraction of the biocomposites, as described in Section 3.6.2. When calculating excess $\mathrm{CH}_{4}$, it was assumed that the PHBV and $2 \mathrm{mPHBV}$ degraded to the same extent as the samples without OWF (average value, $83 \%$ for both). Because there is some uncertainty regarding the extent to which the OWF would be bioavailable, it was notable that degradation of the OWF was observed both in the $\mathrm{CH}_{4}$ production data as well as the post-experimental weight loss measured for the fibers.

Fig. 6 (top panel) shows derivative weight loss as measured by TGA for undegraded and post-degradation OWF. Fig. 6 (bottom panel) shows the overlay of derivative weight loss TGA for the three main components of wood: hemicellulose, cellulose, and lignin. As can be observed in the TGA data, there is a change in the cellulose peak (at $310.6{ }^{\circ} \mathrm{C}$ ) between the pre- and postdegradation samples of the OWF for the $20 \%$ OWF composite data shown. A change in the weight loss above $350{ }^{\circ} \mathrm{C}$ was also observed. A similar trend was observed for the treated $20 \%$ samples and the $40 \%$ untreated sample. This observation is evidence that degradation primarily occurs in the cellulose component of the WF matrix. The composition of OWFis expected to be approximately $38-43 \%$ cellulose, $24-28 \%$ hemicellulose, and 20-26\% lignin [41], so the observed weight loss and $\mathrm{CH}_{4}$ production fall within a reasonable range for partial degradation of the cellulose component.

\section{Conclusions}

A standard methodology was developed to assess $\mathrm{CH}_{4}$ production from and biodegradability of composites undergoing anaerobic degradation in a simulated landfill or AD environment. This methodology was then applied to injection molded PHBV-WF composites with two fiber-matrix compatibilization treatments chosen for in-service performance. In order to predict $\mathrm{CH}_{4}$ production during biodegradation of the composites, the test for wastewater organic matter, COD, was modified to measure lignocellulose and composite materials, providing a quick and simple method to evaluate organic carbon content and predict theoretical $\mathrm{CH}_{4}$ production. Actual $\mathrm{CH}_{4}$ production was measured and experimental values were fit using a modified Gompertz growth model for batch anaerobic systems, which provided a good fit for the $\mathrm{CH}_{4}$ production data for all samples $\left(R^{2}>0.99\right)$. Lag time to initiation of $\mathrm{CH}_{4}$ production, maximum production rate, and ultimate $\mathrm{CH}_{4}$ production were quantified and used to determine the impact of fiber fraction and fiber-matrix compatibilization treatments on composite biodegradation. Lag time for $\mathrm{CH}_{4}$ production decreased linearly with increasing WF fraction, and was not affected by the treatments. The decrease in lag time can be attributed to increased surfaces for microbial enzymatic hydrolysis introduced by fibers at the composite surface. While a linear dependence on $\mathrm{CH}_{4}$ production rate with fiber fraction was not observed, the rate was minimally influenced by fiber fraction, with statistically significant rate increases for silane-treated composites. The extent of biodegradation of the composites (i.e., ultimate $\mathrm{CH}_{4}$ production) was not affected by treatments and decreased linearly with increasing WF, due to incomplete biodegradation of the WF. Partial
WF biodegradation likely resulted from degradation of the cellulose component. Overall, this study suggests that these compatibilization treatments had minimal impacts on anaerobic degradation and that further optimization of this material system can focus on in-service properties without negatively impacting biodegradability potential at end-of-life.

\section{Acknowledgments}

The authors thank BioProcess Control, SeaHold LLC, and Team Biogas for their generous support and collaboration with the AMPTS II. We also thank the City of San Jose and the employees of the San Jose Waste Water Treatment Plant for their assistance in obtaining inoculum for these experiments. Part of this work was performed at the Stanford Nano Shared Facilities (SNSF) and Soft and Hybrid Materials Facility (SMF) at Stanford University. This work was funded by CalRecycle [DRRR10020], California EPA Department of Toxic Substances Control [07T3451], NSF CMMI [0900325], an unrestricted gift from Chevron, and individual graduate funding from the EPA Star Graduate Fellowship and the Stanford Civil Engineering Charles H. Leavell Graduate Fellowship.

\section{Appendix A. Supplementary material}

Supplementary data associated with this article can be found, in the online version, at http://dx.doi.org/10.1016/j.compositesa. 2017.01.014.

\section{References}

[1] Mohanty AK, Misra M, Hinrichsen G. Biofibres, biodegradable polymers and biocomposites: an overview. Macromol Mater Eng 2000;276-277(1):1-24.

[2] Mohanty AK, Misra M, Drzal LT. Sustainable bio-composites from renewable resources: opportunities and challenges in the green materials world. J Polym Environ 2002;10(1):19-26.

[3] Office of Resource Conservation and Recovery (5306P). Advancing Sustainable Materials Management: facts and figures report. Tech rep EPA530-R-15-002, U. S. Environmental Protection Agency; 2015.

[4] ASTM, D3171-15: standard test methods for constituent content of composite materials. ASTM International; 2015.

[5] Buswell AM, Mueller HF. Mechanism of methane fermentation. Ind Eng Chem $1952: 44(3): 550-2$

[6] Ryan CA. Sustainable engineering of biopolymer composites: end-of-life degradation mechanisms [PhD thesis]. Stanford University; 2016.

[7] Hach Company. Hach Water Analysis Handbook; 2008.

[8] ASTM, D5526-94(2002): standard test method for determining anaerobic biodegradation of plastic materials under accelerated landfill conditions. ASTM International; 2002.

[9] ASTM, D5210-92(2007): standard test method for determining the anaerobic biodegradation of plastic materials in the presence of municipal sewage sludge. ASTM International; 2007.

[10] Shelton DR, Tiedje JM. General method for determining anaerobic biodegradation potential. Appl Environ Microbiol 1984;47(4):850-7.

[11] Wu WM, Hickey RF, Zeikus JG. Characterization of metabolic performance of methanogenic granules treating brewery wastewater: role of sulfate-reducing bacteria. Appl Environ Microbiol 1991:57(12):3438-49.

[12] Kenealy W, Zeikus JG. Influence of corrinoid antagonists on methanogen metabolism. J Bacteriol 1981;146(1):133-40

[13] Grady Jr CL, Daigger GT, Love NG, Filipe CD. Biological wastewater treatment. CRC press; 2011.

[14] Ryan CA, Billington SL, Criddle CS. Assessment of models for anaerobic biodegradation of a model bioplastic: poly(hydroxybutyrate-cohydroxyvalerate). Bioresour Technol 2017;227:205-13.

[15] American Public Health Association, American Water Works Association, Water Environment Federation, Standard Methods for the Examination of Water and Wastewater, 20th ed., American Public Health Association; 1998.

[16] Zwietering M, Jongenburger I, Rombouts F, Van't Riet K. Modeling of the bacterial growth curve. Appl Environ Microbiol 1990;56(6):1875-81.

[17] Lay J-J, Li Y-Y, Noike T. Mathematical modell for methane production from landfill bioreactor. J Environ Eng 1998:124(8):730-6.

[18] López S, Prieto M, Dijkstra J, Dhanoa M, France J. Statistical evaluation of mathematical models for microbial growth. Int J Food Microbiol 2004;96 (3):289-300.

[19] Vavilin V, Fernandez B, Palatsi J, Flotats X. Hydrolysis kinetics in anaerobic degradation of particulate organic material: an overview. Waste Manage 2008;28(6):939-51. 
[20] Ghatak MD, Mahanta P. Comparison of kinetic models for biogas production rate from saw dust. Carbon 2014;63:35.

[21] Pieja AJ, Rostkowski KH, Criddle CS. Distribution and selection of poly-3hydroxybutyrate production capacity in methanotrophic proteobacteria. Microb Ecol 2011;62(3):564-73.

[22] Myung J, Flanagan JC, Waymouth RM, Criddle CS. Methane or methanoloxidation dependent synthesis of poly(3-hydroxybutyrate-co-3hydroxyvalerate) by obligate type II methanotrophs. Process Biochem 2016;51(5):561-7.

[23] Tsui A, Wright ZC, Frank CW. Biodegradable polyesters from renewable resources. Annu Rev Chem Biomol Eng 2013;4(1):143-70.

[24] Brandl H, Bachofen R, Mayer J, Wintermantel E. Degradation and applications of polyhydroxyalkanoates. Canad J Microbiol 1995;41:143-53.

[25] Gutierrez-Wing MT, Stevens BE, Theegala CS, Negulescu II, Rusch KA. Anaerobic biodegradation of polyhydroxybutyrate in municipal sewage sludge. J Environ Eng 2010;136(7):709-18.

[26] Miller SA, Srubar III WV, Billington SL, Lepech MD. Integrating durability-based service-life predictions with environmental impact assessments of natura fiber-reinforced composite materials. Resour, Conserv Recycl 2015;99:72-83.

[27] Bhardwaj R, Mohanty AK, Drzal LT, Pourboghrat F, Misra M. Renewable resource-based green composites from recycled cellulose fiber and poly(3hydroxybutyrate-co-3-hydroxyvalerate) Bioplastic. Biomacromolecules 2006;7(6):2044-51.

[28] Singh S, Mohanty AK. Wood fiber reinforced bacterial bioplastic composites: fabrication and performance evaluation. Compos Sci Technol 2007;67 (9):1753-63.

[29] Srubar III WV, Pilla S, Wright ZC, Ryan CA, Greene JP, Frank CW, et al. Mechanisms and impact of fiber-matrix compatibilization techniques on the material characterization of PHBV/oak wood flour engineered biobased composites. Compos Sci Technol 2012;72(6):708-15.

[30] Srubar III WV, Miller SA, Lepech MD, Billington SL. Incorporating spatiotemporal effects and moisture diffusivity into a multi-criteria materials selection methodology for wood-polymer composites. Constr Build Mater 2014;71:589-601.

[31] Mohanty A, Khan MA, Hinrichsen G. Surface modification of jute and its influence on performance of biodegradable jute-fabric/biopol composites. Compos Sci Technol 2000;60(7):1115-24.

[32] Katdare A, Chaubal M. Excipient development for pharmaceutical, biotechnology, and drug delivery systems. CRC Press; 2006.

[33] Rowell R, Pettersen R, Tshabalala M. Cell wall chemistry. CRC Press; 2012 [ch 3. p. 33-72].

[34] Wright ZC. Poly(hydroxybutyrate-co-valerate) biodegradable foams the effects of processing, nanoscale additives, and aging [PhD thesis]. Stanford University; 2013.

[35] Kessler MR. Advanced topics in characterization of composites. Trafford Publishing; 2004.

[36] Barham P, Keller A, Otun E, Holmes P. Crystallization and morphology of bacterial thermoplastic: poly-3-hydroxybutyrate. J Mater Sci 1984;19 (9):2781-94.

[37] Mark JE. 126. Poly(hydroxybutyrate). In: Polymer data handbook. Oxford University Press; 2009. p. 741-52.

[38] Mezzanotte V, Bertani R, Innocenti FD, Tosin M. Influence of inocula on the results of biodegradation tests. Polym Degrad Stab 2005;87(1):51-6.

[39] Gartiser S, Wallrabenstein M, Stiene G. Assessment of several test methods for the determination of the anaerobic biodegradability of polymers. J Environ Polym Degrad 1998;6(3):159-73.
[40] Morse MC. Anaerobic biodegradation of biocomposites for the building industry [PhD thesis]. Stanford University; 2010.

[41] Pettersen RC. The chemical composition of wood. In: Rowell RM, editor. The chemistry of solid wood. Washington, DC: American Chemical Society; 1984. p. 57-126.

[42] Carrier M, Loppinet-Serani A, Denux D, Lasnier J-M, Ham-Pichavant F, Cansell $\mathrm{F}$, et al. Thermogravimetric analysis as a new method to determine the lignocellulosic composition of biomass. Biomass Bioenergy 2011;35 (1):298-307.

[43] Cozzani V, Lucchesi A, Stoppato G, Maschio G. A new method to determine the composition of biomass by thermogravimetric analysis. Canad J Chem Eng 1997;75:1-7.

[44] Khezami L, Chetouani A, Taouk B, Capart R. Production and characterisation of activated carbon from wood components in powder: cellulose, lignin, xylan. Powder Technol 2005;157(1-3):48-56 [4th French Meeting on Powder Science and Technology Papers presented at the 4th French meeting on Powder Science and Technology].

[45] Fabiyi JS, McDonald AG. Effect of wood species on property and weathering performance of wood plastic composites. Compos Part A: Appl Sci Manuf 2010;41(10):1434-40.

[46] Kim H-S, Kim S, Kim H-J, Yang H-S. Thermal properties of bio-flour-filled polyolefin composites with different compatibilizing agent type and content. Thermochim Acta 2006;451(1-2):181-8.

[47] Bouafif H, Koubaa A, Perré P, Cloutier A, Riedl B. Wood particle/high-density polyethylene composites: thermal sensitivity and nucleating ability of wood particles. J Appl Polym Sci 2009;113(1):593-600.

[48] Ndiaye D, Tidjani A. Effects of coupling agents on thermal behavior and mechanical properties of wood flour/polypropylene composites. J Compos Mater 2012;46(24):3067-75.

[49] Numata K, Abe H, Iwata T. Biodegradability of poly(hydroxyalkanoate) materials. Materials 2009;2(3):1104-26.

[50] Wool R, Raghavan D, Wagner G, Billieux S. Biodegradation dynamics of polymer-starch composites. J Appl Polym Sci 2000;77(8):1643-57.

[51] Srubar W, Billington S. A micromechanical model for moisture-induced deterioration in fully biorenewable wood-plastic composites. Compos Part A: Appl Sci Manuf 2013;50:81-92.

[52] Budwill K, Fedorak PM, Page WJ. Methanogenic degradation of poly(3hydroxyalkanoates). Appl Environ Microbiol 1992;58(4):1398-401.

[53] Shin P, Kim M, Kim J. Biodegradability of degradable plastics exposed to anaerobic digested sludge and simulated landfill conditions. J Polym Environ 1997;5(1):33-9.

[54] Reischwitz A, Stoppok E, Buchholz K. Anaerobic degradation of poly-3hydroxybutyrate and poly-3-hydroxybutyrate-co-3-hydroxyvalerate. Biodegradation 1998;8(5):313-9.

[55] Abou-Zeid D-M, Müller R-J, Deckwer W-D. Degradation of natural and synthetic polyesters under anaerobic conditions. J Biotechnol 2001;86 (2):113-26.

[56] Gómez EF, Michel Jr FC. Biodegradability of conventional and bio-based plastics and natural fiber composites during composting, anaerobic digestion and long-term soil incubation. Polym Degrad Stab 2013;98(12):2583-91.

[57] Benner R, Maccubbin AE, Hodson RE. Anaerobic biodegradation of the lignin and polysaccharide components of lignocellulose and synthetic lignin by sediment microflora. Appl Environ Microbiol 1984;47(5):998-1004. 